Original Article

\title{
Role of age and comorbidities in mortality of patients with infective endocarditis
}

Carlos Armiñanzas ${ }^{\mathrm{a}, 1}$, Concepción Fariñas-Alvarez ${ }^{\mathrm{b}, 1}$, Jesús Zarauza ${ }^{\mathrm{c}, 1}$, Patricia Muñoz ${ }^{\mathrm{d}}$, Víctor González Ramallo ${ }^{\mathrm{e}}$, Manuel Martínez Sellés ${ }^{\mathrm{f}}$, José $\mathrm{M}^{\mathrm{a}}{ }^{\mathrm{a}}$. Miró Meda ${ }^{\mathrm{g}}$, Juan Manuel Pericás ${ }^{\mathrm{aw}}$, Miguel Ángel Goenaga ${ }^{\mathrm{h}}$, Guillermo Ojeda Burgos ${ }^{\mathrm{i}}$, Regino Rodríguez Álvarez ${ }^{\mathrm{j}}$, Laura Castelo Corral $^{\mathrm{k}}$, Juan Gálvez-Acebal ${ }^{1}$, Francisco Javier Martínez Marcos ${ }^{\mathrm{m}}$, Maria Carmen Fariñas ${ }^{\mathrm{av}, *, 1}$, the Spanish Collaboration on Endocarditis - Grupo de Apoyo al Manejo de la Endocarditis Infecciosa en Espana Study Group, Fernando Fernández Sánchez , Mariam Noureddine $^{\mathrm{n}}$, Gabriel Rosas ${ }^{\mathrm{n}}$, Javier de la Torre Lima ${ }^{\mathrm{n}}$, José Aramendi ${ }^{\circ}$, Elena Bereciartua ${ }^{\circ}$, María José Blanco ${ }^{\circ}$, Roberto Blanco ${ }^{\circ}$, María Victoria Boado ${ }^{\circ}$, Marta Campaña Lázaro ${ }^{\circ}$, Alejandro Crespo ${ }^{\circ}$, Josune Goikoetxea ${ }^{\circ}$, José Ramón Iruretagoyena ${ }^{\circ}$, Josu Irurzun Zuazabal ${ }^{\circ}$, Leire López-Soria ${ }^{\circ}$, Miguel Montejo ${ }^{\circ}$, Javier Nieto ${ }^{\circ}$, David Rodrigo ${ }^{\circ}$, David Rodríguez ${ }^{\circ}$, Regino Rodríguez ${ }^{\circ}$, Yolanda Vitoria ${ }^{\circ}$, Roberto Voces ${ }^{\circ}$, $\mathrm{M}^{\mathrm{a}}$. Victoria García López ${ }^{\mathrm{p}}$, Radka Ivanova Georgieva ${ }^{\mathrm{p}}$, Guillermo Ojeda ${ }^{\mathrm{p}}$, Isabel Rodríguez Bailón ${ }^{\mathrm{p}}$, Josefa Ruiz Morales ${ }^{\mathrm{p}}$, Ana María Cuende ${ }^{\mathrm{q}}$, Tomás Echeverría ${ }^{\mathrm{q}}$, Ana Fuerte ${ }^{\mathrm{q}}$, Eduardo Gaminde ${ }^{\mathrm{q}}$, Miguel Ángel Goenaga ${ }^{\mathrm{q}}$, Pedro Idígoras ${ }^{\mathrm{q}}$, José Antonio Iribarren ${ }^{\mathrm{q}}$, Alberto Izaguirre Yarza ${ }^{\mathrm{q}}$, Xabier Kortajarena Urkola ${ }^{\mathrm{q}}$, Carlos Reviejo ${ }^{\mathrm{q}}$, Rafael Carrasco ${ }^{\mathrm{r}}$, Vicente Climent ${ }^{\mathrm{r}}$, Patricio Llamas ${ }^{\mathrm{r}}$, Esperanza Merino ${ }^{\mathrm{r}}$, Joaquín Plazas ${ }^{\mathrm{r}}$, Sergio Reus ${ }^{r}$, Nemesio Álvarez ${ }^{\mathrm{s}}$, José María Bravo-Ferrer ${ }^{\mathrm{s}}$, Laura Castelo ${ }^{\mathrm{s}}$, José Cuenca ${ }^{\mathrm{s}}$, Pedro Llinares ${ }^{\mathrm{s}}$, Enrique Miguez Rey ${ }^{\mathrm{s}}$, María Rodríguez Mayo ${ }^{\mathrm{s}}$, Efrén Sánchez ${ }^{\mathrm{s}}$, Dolores Sousa Regueiros, Francisco Javier Martínez ${ }^{\mathrm{t}}$, $\mathrm{M}^{\mathrm{a}}$. del Mar Alonso ${ }^{\mathrm{u}}$, Beatriz Castro ${ }^{\mathrm{u}}$,

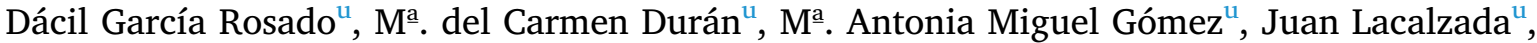
Ibrahim Nassar ${ }^{\mathrm{u}}$, Antonio Plata Ciezar ${ }^{\mathrm{v}}$, José $\mathrm{M}^{\mathrm{a}}$. Reguera Iglesiass ${ }^{\mathrm{v}}$, Víctor Asensi Álvarez ${ }^{\mathrm{w}}$, Carlos Costas $^{\mathrm{w}}$, Jesús de la Hera ${ }^{\mathrm{w}}$, Jonnathan Fernández Suárez ${ }^{\mathrm{w}}$, Lisardo Iglesias Fraile ${ }^{\mathrm{w}}$, Víctor León Arguero ${ }^{\mathrm{w}}$, José López Menéndez ${ }^{\mathrm{w}}$, Pilar Mencia Bajo ${ }^{\mathrm{w}}$, Carlos Morales ${ }^{\mathrm{w}}$, Alfonso Moreno Torricow ${ }^{\mathrm{w}}$, Carmen Palomow ${ }^{\mathrm{w}}$, Begoña Paya Martínez ${ }^{\mathrm{w}}$, Ángeles Rodríguez Esteban ${ }^{\mathrm{w}}$, Raquel Rodríguez García ${ }^{\mathrm{w}}$, Mauricio Telenti Asensiow ${ }^{\mathrm{w}}$, Manuel Almela ${ }^{\mathrm{x}}$, Juan Ambrosioni ${ }^{\mathrm{x}}$, Manuel Azqueta ${ }^{\mathrm{x}}$, Mercè Brunet $^{\mathrm{X}}$, Marta Bodro ${ }^{\mathrm{x}}$, Ramón Cartañá ${ }^{\mathrm{x}}$, Carlos Falces ${ }^{\mathrm{x}}$, Guillermina Fita ${ }^{\mathrm{x}}$, David Fuster ${ }^{\mathrm{x}}$, Cristina García de la Mària ${ }^{\mathrm{x}}$, Marta Hernández-Meneses ${ }^{\mathrm{x}}$, Jaume Llopis Pérez ${ }^{\mathrm{x}}$, Francesc Marco ${ }^{\mathrm{x}}$, José M. Miró ${ }^{\mathrm{x}}$, Asunción Moreno ${ }^{\mathrm{x}}$, David Nicolás ${ }^{\mathrm{x}}$, Salvador Ninot ${ }^{\mathrm{x}}$, Eduardo Quintana ${ }^{\mathrm{x}}$, Carlos Paré ${ }^{\mathrm{x}}$, Daniel Pereda ${ }^{x}$, Juan M. Pericás ${ }^{x}$, José L. Pomar ${ }^{x}$, José Ramírez ${ }^{x}$, Irene Rovira ${ }^{x}$, Elena Sandoval ${ }^{x}$, Marta Sitges $^{\mathrm{x}}$, Dolors Soy ${ }^{\mathrm{x}}$, Adrián Téllez ${ }^{\mathrm{x}}$, José M. Tolosana ${ }^{\mathrm{x}}$, Bárbara Vidal ${ }^{\mathrm{x}}$, Jordi Vila ${ }^{\mathrm{x}}$, Iván Adán ${ }^{\mathrm{y}}$, Javier Bermejo ${ }^{\mathrm{y}}$, Emilio Bouza ${ }^{\mathrm{y}}$, Daniel Celemín ${ }^{\mathrm{y}}$, Gregorio Cuerpo Caballero ${ }^{\mathrm{y}}$,

\footnotetext{
* Corresponding author at: Infectious Diseases Unit, Hospital Universitario Marqués de Valdecilla. University of Cantabria, Santander, 39008, Spain.

${ }^{1}$ Carlos Armiñanzas, Concepción Fariñas-Alvarez, Jesus Zarauza and Maria Carmen Fariñas contributed equally to this manuscript

E-mail addresses: carminanzas@humv.es (C. Armiñanzas), mariaconcepcion.farinas@scsalud.es (C. Fariñas-Alvarez), jesus.zarauza@scsalud.es (J. Zarauza), pmunoz@micro.hggm.es (P. Muñoz), vgramallo@orange.es (V. González Ramallo), mmselles@secardiologia.es (M. Martínez Sellés), jmmiro@clinic.ub.es (J.M. Miró Meda), jpericas@clinic.ub.es (J.M. Pericás), reginorodriguezalvarez@osakidetza.eus (R. Rodríguez Álvarez), jga@us.es (J. Gálvez-Acebal), mcfarinas@humv.es (M.C. Fariñas).
} 
Antonia Delgado Montero ${ }^{y}$, Ana Fernández $\mathrm{Cruz}^{\mathrm{y}}$, Ana García Mansilla ${ }^{\mathrm{y}}$, $\mathrm{M}^{\mathrm{a}}$. Eugenia García Leoni ${ }^{\mathrm{y}}$, Víctor González Ramallo ${ }^{\mathrm{y}}$, Martha Kestler Hernández ${ }^{\mathrm{y}}$, Amaia Mari Hualde ${ }^{\mathrm{y}}$, Mercedes Marín ${ }^{\mathrm{y}}$, Manuel Martínez-Sellés ${ }^{\mathrm{y}}, \mathrm{M}^{\mathrm{a}}$. Cruz Menárguez ${ }^{\mathrm{y}}$, Patricia Muñoz ${ }^{y}$, Cristina Rincón ${ }^{y}$, Hugo Rodríguez-Abella ${ }^{y}$, Marta Rodríguez-Créixems ${ }^{y}$, Blanca Pinilla ${ }^{\mathrm{y}}$, Ángel Pinto ${ }^{\mathrm{y}}$, Maricela Valerio ${ }^{\mathrm{y}}$, Pilar Vázquez ${ }^{\mathrm{y}}$, Eduardo Verde Moreno ${ }^{\mathrm{y}}$, Isabel Antorrena ${ }^{z}$, Belén Loeches ${ }^{z}$, Alejandro Martín Quirós ${ }^{z}$, Mar Morenoz ${ }^{z}$ Ulises Ramírez ${ }^{z}$, Verónica Rial Bastón ${ }^{z}$, María Romero ${ }^{z}$, Araceli Saldaña ${ }^{z}$, Jesús Agüero Balbín ${ }^{\text {aa }}$, Cristina Amado ${ }^{\text {aa }}$, Carlos Armiñanzas Castillo aa , Ana Arnaiz García ${ }^{\text {aa }}$, Manuel Cobo Belaustegui ${ }^{\text {aa }}$, María Carmen Fariñas ${ }^{\mathrm{aa}}$, Concepción Fariñas-Álvarez ${ }^{\mathrm{aa}}$, Rubén Gómez Izquierdo ${ }^{\mathrm{aa}}$, Iván García ${ }^{\text {aa }}$,

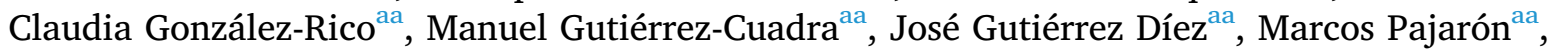
José Antonio Parra ${ }^{\text {aa }}$, Aurelio Sarralde ${ }^{\text {aa }}$, Ramón Teira ${ }^{\text {aa }}$, Jesús Zarauza ${ }^{\text {aa }}$, Fernando Domínguez $^{\mathrm{ab}}$, Pablo García Pavía ${ }^{\mathrm{ab}}$, Jesús González ${ }^{\mathrm{ab}}$, Beatriz Orden ${ }^{\mathrm{ab}}$, Antonio Ramos ${ }^{\mathrm{ab}}$, Tomasa Centella ${ }^{\mathrm{ac}}$, José Manuel Hermida ${ }^{\mathrm{ac}}$, José Luis Moya ${ }^{\mathrm{ac}}$, Pilar Martín-Dávila ${ }^{\text {ac }}$, Enrique Navas ${ }^{\text {ac }}$, Enrique Oliva ${ }^{\text {ac }}$, Alejandro del Río ${ }^{\text {ac }}$, Soledad Ruiz ${ }^{\text {ac }}$, Carmen Hidalgo Tenorio ${ }^{\text {ad }}$, Manuel Almendro Delia ${ }^{\text {ae }}$, Omar Araji ${ }^{\text {ae }}$, José Miguel Barquero ${ }^{\text {ae }}$, Román Calvo Jambrina $^{\mathrm{ae}}$, Marina de Cueto ${ }^{\mathrm{ae}}$, Juan Gálvez Acebal ${ }^{\mathrm{ae}}$, Irene Méndez ${ }^{\mathrm{ae}}$, Isabel Morales ${ }^{\text {ae }}$, Luis Eduardo López-Cortés ${ }^{\text {ae }}$, Arístides de Alarcón ${ }^{\text {af }}$, Emilio García ${ }^{\text {af }}$, Juan Luis Haro $^{\text {af }}$, José Antonio Lepe ${ }^{\text {af }}$, Francisco López ${ }^{\text {af }}$, Rafael Luque ${ }^{\text {af }}$, Luis Javier Alonso ${ }^{\text {ag }}$, Pedro Azcárate ${ }^{\mathrm{ag}}$, José Manuel Azcona Gutiérrez ${ }^{\mathrm{ag}}$, José Ramón Blanco ${ }^{\mathrm{ag}}$, Lara García-Álvarez ${ }^{\mathrm{ag}}$, José Antonio Oteo $^{\text {ag }}$, Mercedes Sanz ${ }^{\text {ag }}$, Natividad de Benito ${ }^{\text {ah }}$, Mercé Gurguí ${ }^{\text {ah }}$, Cristina Pacho ${ }^{\text {ah }}$, Roser Pericas $^{\text {ah }}$, Guillem Pons ${ }^{\text {ah }}$, M. Álvarez ${ }^{\text {ai }}$, A.L. Fernández ${ }^{\text {ai }}$, Amparo Martínez $^{\text {ai }}$, A. Prieto ${ }^{\text {ai }}$, Benito Regueiro $^{\text {ai }}$, E. Tijeira ${ }^{\text {ai }}$, Marino Vega ${ }^{\text {ai }}$, Andrés Canut Blasco ${ }^{\text {aj }}$, José Cordo Mollar ${ }^{a j}$, Juan Carlos Gainzarain Arana ${ }^{\text {aj }}$, Oscar García Uriarte ${ }^{\text {aj }}$, Alejandro Martín López ${ }^{\text {aj }}$, Zuriñe Ortiz de Zárate ${ }^{\mathrm{aj}}$, José Antonio Urturi Matos ${ }^{\mathrm{aj}}$, Gloria García Domínguez ${ }^{\text {ak }}$, Antonio Sánchez-Porto ${ }^{\text {ak }}$, José Mํa ${ }^{\text {. Arribas Leal }}{ }^{\mathrm{al}}$, Elisa García Vázquez ${ }^{\mathrm{al}}$, Alicia Hernández Torres ${ }^{\text {al }}$, Ana Blázquez ${ }^{\text {al }}$, Gonzalo de la Morena Valenzuela ${ }^{a}$, Ángel Alonso ${ }^{\text {am }}$, Javier Aramburu $^{\mathrm{am}}$, Felicitas Elena Calvo ${ }^{\text {am }}$, Anai Moreno Rodríguez ${ }^{\mathrm{am}}$,

Paola Tarabini-Castellani $^{\text {am }}$, Eva Heredero Gálvez ${ }^{\text {an }}$, Carolina Maicas Bellido ${ }^{\text {an }}$, José Largo Pau ${ }^{\text {an }}$, $M^{\mathrm{a}}$. Antonia Sepúlveda ${ }^{\text {an }}$, Pilar Toledano Sierra ${ }^{\text {an }}$, Sadaf Zafar Iqbal-Mirza ${ }^{\text {an }}$,

Eva Cascales Alcolea $^{\text {ao }}$, Pilar Egea Serrano ${ }^{\mathrm{ao}}$, José Joaquín Hernández Roca ${ }^{\text {ao }}$, Ivan Keituqwa Yañez ${ }^{\mathrm{ao}}$, Ana Peláez Ballesta ${ }^{\mathrm{ao}}$, Víctor Soriano ${ }^{\mathrm{ao}}$, Eduardo Moreno Escobar ${ }^{\mathrm{ap}}$, Alejandro Peña Monje $^{\text {ap }}$, Valme Sánchez Cabrera ${ }^{\text {ap }}$, David Vinuesa García ${ }^{\text {ap }}$, María Arrizabalaga Asenjo ${ }^{\text {aq }}$, Carmen Cifuentes Luna ${ }^{\text {aq }}$, Juana Núñez Morcillo ${ }^{\text {aq }}$, $\mathrm{M}^{\mathrm{a}}$. Cruz Pérez Seco ${ }^{\mathrm{aq}}$, Aroa Villoslada Gelabert ${ }^{\mathrm{aq}}$, Carmen Aured Guallar ${ }^{\mathrm{ar}}$, Nuria Fernández Abad ${ }^{\text {ar }}$, Pilar García Mangas ${ }^{\text {ar }}$, Marta Matamala Adell ${ }^{\text {ar }}$, $M^{\mathrm{a}}$. Pilar Palacián Ruiz ${ }^{\text {ar }}$, Juan Carlos Porres ${ }^{\text {ar }}$, Begoña Alcaraz Vidal ${ }^{\text {as }}$, Nazaret Cobos Trigueros $^{\text {as }}$, María Jesús Del Amor Espín ${ }^{\text {as }}$, José Antonio Giner Caro ${ }^{\text {as }}$, Roberto Jiménez Sánchez ${ }^{\text {as }}$, Amaya Jimeno Almazán ${ }^{\text {as }}$, Alejandro Ortín Freire ${ }^{\text {as }}$, Monserrat Viqueira González ${ }^{\text {as }}$, Pere Pericás Ramis ${ }^{\text {at }}, M^{a}$. Ángels Ribas Blanco ${ }^{\text {at }}$, Enrique Ruiz de Gopegui Bordes ${ }^{\text {at }}$, Laura Vidal Bonet ${ }^{\text {at }}, \mathrm{M}^{\mathrm{a}}$. Carmen Bellón Munera ${ }^{\text {au }}$, Elena Escribano Garaizabal ${ }^{\text {au }}$, Antonia Tercero Martínez ${ }^{\text {au }}$, Juan Carlos Segura Luque ${ }^{\text {au }}$

\footnotetext{
${ }^{a}$ Infectious Diseases Unit, Hospital Universitario Marqués de Valdecilla, University of Cantabria, IDIVAL, Santander, Spain

${ }^{\mathrm{b}}$ Division of Health Care Quality, Hospital Universitario Marqués de Valdecilla, IDIVAL, Santander, Spain

${ }^{\mathrm{c}}$ Hospital Universitario Marqués de Valdecilla, Santander, Spain

${ }^{\mathrm{d}}$ Servicio de Microbiología Clínica y Enfermedades Infecciosas, Hospital General Universitario Gregorio Marañón, Madrid, Instituto de Investigación Sanitaria Gregorio Marañón, CIBER Enfermedades Respiratorias-CIBERES (CB06/06/0058), Facultad de Medicina, Universidad Complutense de Madrid, Spain

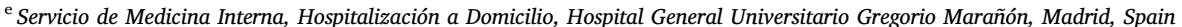

${ }^{\mathrm{f}}$ Servicio de Cardiología, Hospital General Universitario Gregorio Marañón, Madrid, Universidad Europea, Universidad Complutense, Madrid, Spain

${ }^{\mathrm{g}}$ Servicio de Enfermedades Infecciosas, Hospital Clinic-IDIBAPS, Universidad de Barcelona, Barcelona, Spain

${ }^{\mathrm{h}}$ Servicio de Enfermedades Infecciosas, Hospital Universitario Donosti, San Sebastián, Spain

${ }^{\mathrm{i}}$ Servicio de Medicina Interna, Hospital Universitario Virgen de la Victoria, Málaga, Spain

${ }^{\mathrm{j}}$ Unidad de Enfermedades Infecciosas, Hospital Universitario de Cruces, Bilbao, Universidad del País Vasco, País Vasco, Spain

${ }^{\mathrm{k}}$ Servicio de Enfermedades Infecciosas, Complejo Hospitalario A Coruña, A Coruña, Spain

${ }^{1}$ JUnidad Clínica de Enfermedades Infecciosas y Microbiología, Hospital Universitario Virgen Macarena Instituto de Biomedicina de Sevilla, IBIS, Universidad de Sevilla, Sevilla, Spain

m Servicio de Enfermedades Infecciosas, Hospital Juan Ramón Jiménez. Huelva, Spain

${ }^{\mathrm{n}}$ Hospital Costa del Sol, Marbella, Spain

${ }^{\circ}$ Hospital Universitario de Cruces, Bilbao, Spain
} 
${ }^{\mathrm{p}}$ Hospital Universitario Virgen de la Victoria, Málaga, Spain

${ }^{\mathrm{q}}$ Hospital Universitario Donostia-Policlínica Gipuzkoa, San Sebastián, Spain

${ }^{\mathrm{r}}$ Hospital General Universitario de Alicante, Alicante, Spain

${ }^{\mathrm{s}}$ Complejo Hospitalario Universitario A Coruña, A Coruña, Spain

${ }^{\mathrm{t}}$ Complejo Hospitalario Universitario de Huelva, Huelva, Spain

${ }^{\mathrm{u}}$ Hospital Universitario de Canarias, Canarias, Spain

${ }^{\mathrm{v}}$ Hospital Regional Universitario de Málaga, Málaga, Spain

${ }^{\mathrm{w}}$ Hospital Universitario Central Asturias, Oviedo, Spain

${ }^{\mathrm{x}}$ Hospital Clínic-IDIBAPS, Universidad de Barcelona, Barcelona, Spain

${ }^{y}$ Hospital General Universitario Gregorio Marañón, Madrid, Spain

${ }^{\mathrm{z}}$ Hospital Universitario La Paz, Madrid, Spain

${ }^{\text {aa }}$ Universitario Marqués de Valdecilla, Santander, Spain

${ }^{\text {ab }}$ Hospital Universitario Puerta de Hierro, Madrid

${ }^{\text {ac }}$ Hospital Universitario Ramón y Cajal, Madrid, Spain

${ }^{\mathrm{ad}}$ Hospital Universitario Virgen de las Nieves, Granada, Spain

${ }^{\text {ae } H o s p i t a l}$ Universitario Virgen Macarena, Sevilla, Spain

${ }^{\text {af }}$ Hospital Universitario Virgen del Rocío, Sevilla, Spain

${ }^{\text {ag }}$ Hospital San Pedro, Logroño, Spain

${ }^{\text {ah }}$ Hospital de la Santa Creu i Sant Pau, Barcelona, Spain

${ }^{\text {ai }}$ Complejo Hospitalario Universitario de Santiago de Compostela, A Coruña, Spain

${ }^{\text {aj }}$ Hospital Santiago Apóstol, Vitoria, Spain

${ }^{\mathrm{ak}}$ Hospital SAS Línea de la Concepción, Cádiz, Spain

${ }^{\text {al } H o s p i t a l ~ C l i ́ n i c o ~ U n i v e r s i t a r i o ~ V i r g e n ~ d e ~ l a ~ A r r i x a c a ~ M u r c i a, ~ S p a i n ~}$

${ }^{\text {am }}$ Hospital de Txagorritxu, Vitoria, Spain

${ }^{\text {an }}$ Hospital Virgen de la Salud, Toledo, Spain

ao Hospital Rafael Méndez, Lorca, Murcia, Spain

${ }^{\text {ap }}$ Hospital Universitario San Cecilio Granada, Spain

${ }^{\mathrm{aq}}$ Hospital Son Llátzer Palma de Mallorca, Spain

${ }^{\text {ar }}$ Hospital Universitario Miguel Servet Zaragoza, Spain

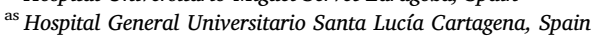

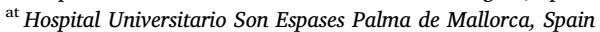

${ }^{\text {au }}$ Complejo Hospitalario Universitario de Albacete Albacete, Spain

${ }^{\text {av }}$ Maria Carmen Fariñas, Infectious Diseases Unit, Hospital Universitario Marqués de Valdecilla, IDIVAL, University of Cantabria, Santander, Spain

${ }^{\text {aw }}$ Servicio de Enfermedades Infecciosas, Hospital Clinic de Barcelona-IDIBAPS. Barcelona, Spain

\section{A R T I C L E I N F O}

\section{Keywords:}

Endocarditis

Age

Charlson index

Comorbidity

Surgery

\begin{abstract}
A B S T R A C T
Purpose: The aim of this study was to analyse the characteristics of patients with IE in three groups of age and to assess the ability of age and the Charlson Comorbidity Index (CCI) to predict mortality-

Methods: Prospective cohort study of all patients with IE included in the GAMES Spanish database between 2008 and 2015.Patients were stratified into three age groups: $<65$ years, 65 to 80 years,and $\geq 80$ years. The area under the receiver-operating characteristic (AUROC) curve was calculated to quantify the diagnostic accuracy of the CCI to predict mortality risk.

Results: A total of 3120 patients with IE $(1327<65$ years; $129165-80$ years;502 $\geq 80$ years $)$ were enrolled.Fever and heart failure were the most common presentations of IE, with no differences among age groups.Patients $\geq 80$ years who underwent surgery were significantly lower compared with other age groups (14.3\%,65 years; $20.5 \%, 65-79$ years; $31.3 \%$, $\geq 80$ years). In-hospital mortality was lower in the $<65$-year group $(20.3 \%,<65$ years;30.1\%,65-79 years;34.7\%, $\geq 80$ years; $p<0.001)$ as well as 1-year mortality $(3.2 \%$, < 65 years; $5.5 \%$, 65-80 years; $7.6 \%, \geq 80$ years; $p=0.003)$.Independent predictors of mortality were age $\geq 80$ years (hazard ratio [HR]:2.78;95\% confidence interval [CI]:2.32-3.34), CCI $\geq 3$ (HR:1.62; 95\% CI:1.39-1.88), and non-performed surgery (HR:1.64;95\% CI:11.16-1.58). When the three age groups were compared,the AUROC curve for CCI was significantly larger for patients aged $<65$ years $(p<0.001)$ for both in-hospital and 1-year mortality.

Conclusion: There were no differences in the clinical presentation of IE between the groups. Age $\geq 80$ years, high comorbidity (measured by CCI), and non-performance of surgery were independent predictors of mortality in patients with IE.CCI could help to identify those patients with IE and surgical indication who present a lower risk of in-hospital and 1-year mortality after surgery, especially in the $<65$-year group.
\end{abstract}

\section{Introduction}

Infective endocarditis (IE) is a life-threatening disease with high morbidity and mortality [1-4]. Its incidence in older patients has increased for different reasons, such as the aging of the general population and the increasing percentage of comorbidities [5-14]. Clinical presentation seems to be similar between the younger and older population [15-19]; however, there is no agreement on the role of age in general mortality or in the mortality related to surgery as a treatment for IE $[2,8,10]$.

On the other hand, international guidelines have established the indication for surgery (repair or valve replacement) in certain situations, such as valve dysfunction resulting in heart failure, abscess, recurrent embolic events with residual vegetation, persistent bacteraemia, or especially aggressive microorganisms (i.e., Staphylococcus aureus) [20-22]; however, there are no recommendations in the guidelines addressing the elderly population. Moreover, in patients with IE, several scores have been proposed to predict early mortality after surgery with the goal of helping physicians make the most appropriate surgical decision. Although these scores could be applied to elderly patients, a specific risk score system for this population may be necessary $[13,23,24]$.

Among scores of burdens of chronic diseases, the Charlson Comorbidity Index (CCI) $[25,26]$ is a well-known scale designed to 
estimate the baseline situation and prognosis of patients based on a range of medical conditions. Easy to apply, objective, and reproducible, the classical "3-points-cutoff" of the CCI has been studied in different clinical situations [27-29], and it has been related to a high burden of comorbidity.

The objectives of our study were to analyse the epidemiological characteristics of IE in three different age groups of patients ( $<65$ years, $65-79$ years, and $\geq 80$ years) and to assess the weight of aging and comorbidity to predict the in-hospital and 1-year mortality risk in each group.

\section{Methods}

\subsection{Study population}

All consecutive patients with definite or possible IE, according to the modified Duke criteria [30,31], were prospectively included in the Spanish Collaboration on Endocarditis-Grupo de Apoyo al Manejo de la Endocarditis infecciosa en España (GAMES) registry maintained by 39 Spanish hospitals from January 2008 to April 2015. Multidisciplinary teams, including infectious disease physicians, cardiologists, heart surgeons, echocardiographers, microbiologists, and imaging specialists, completed standardized case report forms with IE episode and follow-up data that included clinical, microbiological, and echocardiographic sections [32].

\subsection{Ethics}

The study was performed in accordance with the Declaration of Helsinki. The protocol was reviewed and approved by the Institutional Ethics Committee at all participating hospitals, according to local standards. Informed consent was obtained from each patient.

\subsection{Definitions and data collection}

Active IE was defined as endocarditis with at least one of the

Table 1

Characteristics of 3120 patients diagnosed with IE according to three age groups.

\begin{tabular}{|c|c|c|c|c|}
\hline & Patients $<65 y=1327$ & $\begin{array}{l}\text { Patients 65-79y } \\
N=1291\end{array}$ & $\begin{array}{l}\text { Patients } \geq 80 y \\
N=502\end{array}$ & $p$-value ${ }^{\mathrm{a}}$ \\
\hline Male gender, n (\%) & $987(74.4)$ & $835(64.7)$ & $286(57.2)$ & $<0.001$ \\
\hline \multicolumn{5}{|l|}{ Comorbidities, n (\%) } \\
\hline Chronic pulmonary disease & $174(15)$ & $280(24.3)$ & 107 (23.7) & $<0.001$ \\
\hline Coronary arterial disease & $251(19)$ & $388(30.1)$ & $129(25.7)$ & $<0.001$ \\
\hline Congestive heart failure & $336(25.4)$ & $468(36.3)$ & $203(40.5)$ & $<0.001$ \\
\hline Diabetes mellitus & $272(20.5)$ & $433(33.6)$ & $154(30.7)$ & $<0.001$ \\
\hline Solid organ transplant recipients & $35(2.6)$ & $20(1.6)$ & $0(0)$ & 0.001 \\
\hline Moderate/severe renal disease & $170(12.8)$ & $213(16.5)$ & $107(21.4)$ & $<0.001$ \\
\hline Moderate/severe liver disease & $83(6.3)$ & $44(3.4)$ & $5(1)$ & $<0.001$ \\
\hline Charlson Comorbidity Index $\geq 3$ & $405(30.6)$ & $522(40.6)$ & $232(46.2)$ & $<0.001$ \\
\hline \multicolumn{5}{|l|}{ Baseline Cardiac Status, n(\%) } \\
\hline Congenital cardiac disease & $158(11.9)$ & $18(1.4)$ & $4(0.8)$ & $<0.001$ \\
\hline Degenerative valvular disease & $487(36.7)$ & $597(46.2)$ & $275(54.8)$ & $<0.001$ \\
\hline Previous IE & $135(10.2)$ & $77(6)$ & $21(4.2)$ & $<0.001$ \\
\hline Previous cardiac surgery & $382(28.9)$ & $530(41.1)$ & $158(31.6)$ & $<0.001$ \\
\hline \multicolumn{5}{|l|}{ Clinical features at presentation, n (\%) } \\
\hline Fever & $1100(82.9)$ & 1057 (81.9) & $409(81.4)$ & 0.274 \\
\hline Arterial emboli & $429(32.3)$ & $346(26.8)$ & $121(24.1)$ & 0.001 \\
\hline New valvular regurgitation & $498(37.5)$ & $426(33.0)$ & $159(31.7)$ & 0.050 \\
\hline Splenomegaly & $229(17.3)$ & $124(9.6)$ & $27(5.4)$ & $<0.001$ \\
\hline Heart failure & $521(39.2)$ & $521(40.4)$ & $205(40.8)$ & 0.893 \\
\hline Heart block & $103(7.8)$ & $118(9.1)$ & $44(8.8)$ & 0.325 \\
\hline Acute renal insufficiency & $391(29.5)$ & $551(42.7)$ & $189(37.6)$ & $<0.001$ \\
\hline Angor & $9(0.7)$ & $16(1.4)$ & $14(3)$ & 0.003 \\
\hline Septic shock & $187(14.1)$ & $134(10.4)$ & $43(8.6)$ & 0.003 \\
\hline \multicolumn{5}{|c|}{ Epidemiological characteristics of IE, n (\%) } \\
\hline Natural valve affected & $896(67.5)$ & $713(55.2)$ & $311(62)$ & $<0.001$ \\
\hline Prosthetic valve affected & $324(24.4)$ & $482(37.3)$ & $132(26.3)$ & $<0.001$ \\
\hline Endovascular device & $143(10.8)$ & $150(11.3)$ & $82(16.3)$ & 0.004 \\
\hline \multicolumn{5}{|l|}{ Site of acquisition } \\
\hline Community & $837(63.1)$ & $666(51.6)$ & $284(56.7)$ & $<0.001$ \\
\hline Nosocomial & $321(24.4)$ & $458(35.5)$ & $16.5(30.7)$ & \\
\hline Health care related & $124(9.4)$ & $104(8.1)$ & $41(8.2)$ & \\
\hline \multicolumn{5}{|l|}{ Type of affected valve } \\
\hline Aortic & $605(45.6)$ & $685(53.1)$ & $227(45.2)$ & $<0.001$ \\
\hline Mitral & $575(43.3)$ & $555(43)$ & $220(43.8)$ & 0.948 \\
\hline Pulmonary & $37(2.8)$ & $8(0.6)$ & $0(0)$ & $<0.001$ \\
\hline Tricuspid & $108(8.1)$ & $43(3.3)$ & $17(3.4)$ & $<0.001$ \\
\hline \multicolumn{5}{|l|}{ Etiology, n (\%) } \\
\hline S. aureus & $318(24.0)$ & $276(21.4)$ & $100(19.9)$ & 0.099 \\
\hline CNS & $202(15.2)$ & $273(21.1)$ & $72(14.3)$ & $<0.001$ \\
\hline S. bovis & $66(6.0)$ & $89(6.9)$ & $43(8.6)$ & 0.013 \\
\hline S. viridans & $165(12.4)$ & $104(8.1)$ & $49(9.7)$ & 0.001 \\
\hline Enterococcus spp. & $130(9.8)$ & $205(15.8)$ & $96(19.1)$ & $<0.001$ \\
\hline Gramnegative bacilli & 65 (4.9) & $42(3.3)$ & $18(3.6)$ & 0.88 \\
\hline Candida spp. & $20(1.5)$ & $26(2.0)$ & $8(1.6)$ & 0.590 \\
\hline Polimicrobial IE & $28(2.1)$ & 25 (1.9) & $8(1.6)$ & 0.856 \\
\hline No etiology & $122(9.2)$ & $113(8.8)$ & $48(9.6)$ & 0.848 \\
\hline
\end{tabular}

IE: infective endocarditis; CoNS: coagulase-negative staphylococci.

${ }^{\text {a }}$ Two-tailed Chi-squared test or Fisher's exact test as appropriate in each case. 
following: positive blood cultures, fever, leucocytosis, raised inflammation markers, or current antibiotic treatment [30,31]. Microbiological diagnosis was made by blood, valve cultures, and/or molecular techniques. Transthoracic and transoesophageal echocardiography were performed on patients with clinical or microbiological suspicion of IE. To assess comorbidity, the CCI was calculated [23,24]. In-hospital mortality was defined as death, regardless of its cause, that occurred during the hospital admission. One-year mortality was defined as death, regardless of its cause, that occurred within 1 year after hospital discharge. Indication of surgical treatment was considered based on the criteria of American Heart Asociation ${ }^{21}$ and European Society of Cardiology [22].

Data from patients with IE were analysed, including epidemiological and medical conditions, heart valve involvement, clinical manifestations at IE presentation, microorganisms identified, the appropriateness of antibiotic treatment used (defined as appropriate when the selected antibiotic was sensitive to an isolated microorganism, and the dose, dosing interval and duration of treatment were adequate according to the guidelines of IE), and morbidity and mortality during hospitalization. We also evaluated indications for surgery treatment, whether there was a consultation with the cardiac surgery team and its recommendation, and what were the reasons for not performing the surgery. All patients were followed for at least 1-year post-discharge.

\subsection{Statistical analyses}

Quantitative variables were expressed as mean and standard deviation (SD); qualitative variables were expressed as frequency and percentage. Statistical analysis was performed using a two-tailed $\chi^{2}$ test and a Fisher's exact test, or an analysis of variance test, as appropriate in each case. Inhospital mortality and 1-year mortality were defined as all-cause mortality. A multivariate Cox regression model was adjusted to estimate survival rate over time as a function of several covariates. Hazard ratios (HRs) and their $95 \%$ confidence intervals (CIs) were calculated. The area under the receiver-operating characteristic (AUROC) curve with a 95\% CI was calculated to quantify the diagnostic accuracy of the CCI to predict mortality risk. Sensitivity, specificity, and positive and negative predictive values and their 95\% CIs were calculated.

A two-tailed $p<0.05$ was considered statistically significant. Data were analysed using SPSS package v19.0 (SPSS Inc., Chicago, IL) and Stata statistical software (Release 11.0, Stata Corporation, College Station, TX).

\section{Results}

\subsection{Patients characteristics}

During the study period, 3120 patients (67.5\% men) with definite or possible IE were enrolled: 1327 (42.6\%) patients <65 years, 1291 (41.4\%) between 65 and 79 years, and $502(16 \%) \geq 80$ years. Overall, the mean follow-up of IE patients was 386.0 days (range, 14-698 days).

The patients' comorbidities conditions, baseline cardiac status, and clinical and epidemiological characteristics of IE among all three groups are shown in Table 1 . The group aged $\geq 80$ years had a significantly higher percentage of cases with CCI $\geq 3(46.2 \%)$, degenerative valvular disease $(54.8 \%)$, renal disease $(21.4 \%)$, affected natural valve $(62 \%)$, and endovascular device IE (16.3\%) than patients in other age groups. There were no differences among age groups in the proportion with

Table 2

Treatment and outcome of 3120 patients with endocarditis in the three age groups.

\begin{tabular}{|c|c|c|c|c|}
\hline & Patients $<65 \mathrm{y} \mathrm{N}=1327$ & Patients 65-79y N = 1291 & Patients $\geq 80 \mathrm{y} \mathrm{N}=502$ & $p$-value $\mathrm{a}^{\mathrm{a}}$ \\
\hline \multicolumn{5}{|l|}{ Treatment, n(\%) } \\
\hline Appropriate antimicrobial treatment & $1268(95.5)$ & $1233(95.5)$ & $476(94.8)$ & 0.828 \\
\hline Surgical indication & $898(67.7)$ & $858(66.5)$ & $261(52.0)$ & $<0.001$ \\
\hline Surgical performance & $709(53.4)$ & $594(46.0)$ & $104(20.7)$ & $<0.001$ \\
\hline \multicolumn{5}{|l|}{ Indications for surgery, $\mathrm{n}(\%)$} \\
\hline Severe regurgitation & $346(26.1)$ & $230(17.8)$ & $49(9.8)$ & $<0.001$ \\
\hline Myocardial affectation & $127(9.6)$ & $122(9.5)$ & $23(4.6)$ & 0.002 \\
\hline Persistence of sepsis & $62(4.7)$ & $60(4.6)$ & $20(4.0)$ & 0.815 \\
\hline Aggressive microorganism & $169(12.7)$ & $152(11.8)$ & $28(5.6)$ & $<0.001$ \\
\hline Recidive of IE & $15(1.1)$ & $11(0.9)$ & $1(0.2)$ & 0.166 \\
\hline \multicolumn{5}{|l|}{ Prosthetic IE } \\
\hline Early & $59(4.4)$ & $93(7.2)$ & $8(1.6)$ & $<0.001$ \\
\hline Late & $85(6.4)$ & $79(6.1)$ & $19(3.8)$ & 0.099 \\
\hline Heart failure & $319(24.0)$ & $278(21.5)$ & $66(13.1)$ & $<0.001$ \\
\hline Systemic emboli & $72(5.4)$ & $43(3.3)$ & $13(2.6)$ & 0.006 \\
\hline \multicolumn{5}{|l|}{ Reasons for NO surgery, n(\%) } \\
\hline Ictus & $33(2.5)$ & $47(3.6)$ & $18(3.6)$ & 0.231 \\
\hline Intracranial hemorrhage & $29(2.2)$ & $16(1.2)$ & $6(1.2)$ & 0.094 \\
\hline Hemodynamic instability & $43(3.2)$ & $67(5.2)$ & $24(4.8)$ & 0.050 \\
\hline Complexity of surgery & $24(1.8)$ & $38(2.9)$ & $26(5.2)$ & 0.001 \\
\hline Negative of patient & $21(1.6)$ & $43(3.3)$ & $50(10.0)$ & $<0.001$ \\
\hline Negative of surgeon & $58(4.4)$ & $81(6.3)$ & $48(9.6)$ & $<0.001$ \\
\hline Death & $24(1.8)$ & $28(2.2)$ & $17(3.4)$ & 0.154 \\
\hline \multicolumn{5}{|l|}{ Complications after surgery, $\mathrm{n}(\%)$} \\
\hline Ictus & $6(0.5)$ & $14(1.1)$ & $3(0.6)$ & 0.150 \\
\hline Intracranial hemorrhage & $13(1.0)$ & $10(0.8)$ & $1(0.2)$ & 0.258 \\
\hline Hemodynamic instability & $102(7.7)$ & $117(9.1)$ & $18(3.6)$ & 0.001 \\
\hline Surgical site infection & $6(0.5)$ & $5(0.4)$ & $5(1.0)$ & 0.218 \\
\hline Nosocomial pneumonia & $37(2.8)$ & $44(3.4)$ & $10(2.0)$ & 0.273 \\
\hline Sepsis related to catheter & $12(0.9)$ & $20(1.5)$ & $1(0.2)$ & 0.034 \\
\hline Renal failure & $74(5.6)$ & $95(7.4)$ & $15(3.0)$ & 0.002 \\
\hline Cardiac blockage & $35(2.6)$ & $35(2.7)$ & $9(1.8)$ & 0.562 \\
\hline \multicolumn{5}{|l|}{ Outcome, n(\%) } \\
\hline In-hospital mortality & $270(20.3)$ & $388(30.1)$ & $174(34.7)$ & $<0.001$ \\
\hline 1 -year mortality & $60(11.2)$ & $95(11.7)$ & $59(20.4)$ & $<0.001$ \\
\hline
\end{tabular}

IE: infective endocarditis. MOD: multiple organ dysfunction. CNS: coagulase-negative Staphylococci.

a Two-tailed Chi-squared test or Fisher's exact test (as appropriate in each case). 
Table 3

Predictors of mortality in 3120 patients with IE.

\begin{tabular}{lll}
\hline & HR $(95 \% \mathrm{CI})$ & Adjusted HR $\mathrm{HR}^{\mathrm{a}}$ (95\% IC) \\
\hline $\begin{array}{l}\text { Age, years } \\
\quad<66\end{array}$ & 1 & 1 \\
$\quad 66-80$ & $1.59(1.38-1.84)$ & $1.56(1.32-1.84)$ \\
$\quad>80$ & $2.17(1.83-2.58)$ & $2.05(1.67-2.50)$ \\
Age, years (per year) & $1.023(1.018-1.028)$ & $1.021(1.016-1.027)$ \\
Female sex (ref.: male) & $1.34(1.18-1.52)$ & $1.14(0.98-1.32)$ \\
Charlson Comorbidity Index $\geq 3$ & $1.93(1.69-2.20)$ & $1.62(1.39-1.88)$ \\
Prosthetic valve IE & $1.23(1.08-1.40)$ & $1.16(1.00-1.35)$ \\
Nosocomial IE & $1.56(1.37-1.78)$ & $1.21(1.04-1.40)$ \\
Sepsis with MOD & $2.60(2.26-2.99)$ & $1.72(1.46-2.04)$ \\
Septic shock & $3.80(3.28-4.39)$ & $2.78(2.32-3.34)$ \\
Abscess & $1.65(1.41-1.93)$ & $1.60(1.34-1.91)$ \\
S. aureus IE & $1.70(1.48-1.94)$ & $1.34(1.14-1.58)$ \\
No surgery & $1.64(1.44-1.87)$ & $1.36(1.16-1.58)$ \\
& &
\end{tabular}

IE: infective endocarditis. HR: hazard ratio; CI: confidence interval. MOD: multiple organ dysfunction.

a Multivariate Cox regression: adjusted by age, sex, Charlson Index $\geq 3$, nosocomial valve IE, prosthetic valve IE, presence of abscess, sepsis with MOD, septic shock, $S$. aureus IE and performance of surgery.

fever as a clinical presentation of IE. However, patients aged $<65$ years presented a significantly higher frequency of septic shock (14.1\%), new valvular regurgitation (37.5\%), and splenomegaly (17.5\%). Other clinical data presented at the time of the diagnosis are shown in Table 1.

\subsection{Etiology}

Overall, $S$. aureus was the most common microorganism isolated (22.2\%), followed by coagulase-negative staphylococci (CoNS) (17.5\%), Enterococcus spp. (13.8\%), and Streptococcus viridans (10.2\%). S. viridans was significantly more common in patients aged $<65$ years (12.4\%), while CoNS was prevalent in the 65- to 80-year group (21.1\%) and both Streptococcus bovis and enterococci were noted in the $\geq 80$ year group (8.6\% and $19.1 \%$, respectively). Gram-negative bacilli and Candida spp. were similar among groups, as was the proportion of IE without microbiologic isolation (Table 1).

\subsection{Treatment}

The appropriateness of antibiotic treatment in the three groups of patients was $>90 \%$, without statistically significant differences between them (Table 2). There was a significant difference between the proportion of patients who had surgical indication and those who underwent surgery; this difference increased significantly with age: $14.3 \%, 20.5 \%$, and $31.3 \%$ in patients $<65$ years, 65 to 79 years, and $\geq 80$ years, respectively. Patients $\geq 80$ years who underwent surgery had significantly less hemodynamic instability $(3.6 \%)$, renal failure (3\%), and cardiac blockage (1.8\%) as complications of surgery than the other groups of patients (Table 2).

\subsection{Outcome}

In the $\geq 80$-year group, there was a significantly higher in-hospital mortality (34.7\%) and one-year mortality (20.4\%) (Table 2). To analyse the role of age, comorbidity, and performance of surgery on mortality, multivariate Cox regression models were performed (Table 3). The main independent predictors of mortality were septic shock (adjusted HR: 2.78 [95\% CI: 2.32-3.34] and age $\geq 80$ years (adjusted HR: 2.05 [95\% CI: 1.67-2.50]). CCI $\geq 3$ presented an adjusted HR of 1.62 (95\% CI: 1.39-1.88), and non-performance of surgery had an adjusted HR of 1.36 (95\% CI: 1.16-1.58).

Patients with surgical indication ( $n=2011$ ) were analysed separately, comparing their outcome regarding whether or not surgery was performed. There were many significant differences in the characteristics
Table 4

Characteristics of 2011 patients with IE and surgical indication, according to performance of surgery.

\begin{tabular}{llll}
\hline & $\begin{array}{l}\text { Surgery } \\
(n=1368)\end{array}$ & $\begin{array}{l}\text { No surgery } \\
(n=643)\end{array}$ & $p$-value \\
& $1015(74.3)$ & $409(63.5)$ & $<0.001$ \\
Male, n(\%) & $62.2(15.5)$ & $69.5(14.7)$ & $<0.001$ \\
Age (years), mean value \pm SD & $694(50.7)$ & $204(31.4)$ & $<0.001$ \\
Age < 65y, n (\%) & $577(42.11)$ & $281(43.43)$ & 0.577 \\
Age 65-79, n (\%) & $99(7.2)$ & $162(25)$ & $<0.001$ \\
Age $\geq 80 y, n$ (\%) & $1.9(1.8)$ & $2.9(2.3)$ & $<0.001$ \\
CCI, mean value \pm SD & $405(29.6)$ & $311(48.4)$ & $<0.001$ \\
CCI $\geq 3, \mathrm{n}$ (\%) & & & \\
Type of IE, n (\%) & $775(56.6)$ & $408(63.1)$ & 0.006 \\
$\quad$ Native & $976(71.2)$ & $419(64.8)$ & 0.003 \\
$\quad$ Prosthesis & $1087(79.9)$ & $552(85.7)$ & 0.002 \\
Fever, n(\%) & $802(58.7)$ & $400(62.1)$ & 0.147 \\
New valvular regurgitation, n & & & \\
$\quad$ (\%) & $676(49.4)$ & $347(53.8)$ & 0.064 \\
Heart failure, n(\%) & $212(15.5)$ & $156(24.2)$ & $<0.001$ \\
Sepsis with MOD, n(\%) & $148(10.8)$ & $128(19.8)$ & $<0.001$ \\
Septic shock, n(\%) & & & \\
Main microorganisms, n(\%) & $241(17.6)$ & $197(30.4)$ & $<0.001$ \\
$\quad$ S. aureus & $311(22.7)$ & $110(17)$ & 0.003 \\
CNS & $62(5.2)$ & $34(5.9)$ & 0.525 \\
S. bovis & $152(12.8)$ & $47(8.2)$ & 0.005 \\
S. viridans & $304(22.2)$ & $352(54.4)$ & $<0.001$ \\
In-hospital mortality, n (\%) & $64(6.6)$ & $57(21.3)$ & $<0.001$ \\
One-year mortality, n (\%) & & & \\
\hline
\end{tabular}

IE: infective Endocarditis. SD: standard deviation. CCI: Charlson Comorbidity Index. MOD: multiple organ dysfunction. CNS: coagulase-negative Staphylococci.

a Two-tailed Chi-squared test or Fisher's exact test (as corresponding) for categorical variables and ANOVA test for continuous variables.

between the 2 groups, with higher values among non-operated patients, highlighting the following variables: proportion of patients aged $\geq 80$ years ( $25 \%$ vs. $7.2 \%$ ), CCI $\geq 3(48.4 \%$ vs. $29.6 \%$ ), sepsis with multiple organ dysfunction ( $24.2 \%$ vs. $15.5 \%)$, S. aureus IE (30.4\% vs. $17.6 \%)$, in-hospital mortality ( $54.4 \%$ vs. $22.2 \%)$, and 1-year mortality $(21.3 \%$ vs. 6.6\%). Other significant differences are shown in Table 4.

Among patients who finally underwent surgery $(n=1370)$, those with CCI $\geq 3$ had significant differences in the distribution of the following variables: male gender, age, septic shock, in-hospital mortality, and 1-year mortality (Table 5).

Table 5

Characteristics of 1370 patients with IE operated, grouped by Charlson Comorbidity Index (CCI) score $<3$ and $\geq 3$.

\begin{tabular}{lllc}
\hline & $\begin{array}{l}\mathrm{CCI} \geq 3 \\
(n=406)\end{array}$ & $\begin{array}{l}\mathrm{CCI}<3 \\
(n=964)\end{array}$ & p-value $^{\mathrm{a}}$ \\
\hline $\begin{array}{lll}\text { Male, n(\%) } \\
\text { Age (years), mean value } \pm\end{array}$ & $\begin{array}{l}317(78.0) \\
\quad 65.8(12.3)\end{array}$ & $698(72.6)$ & 0.042 \\
$\quad$ SD & $186(45.81)$ & $523(54.2)$ & $<0.001$ \\
Age $<$ 65y, n (\%) & $183(45.07)$ & $380(39,5)$ & 0.004 \\
Age 65-79, n (\%) & $37(9.1)$ & $61(6.3)$ & 0.066 \\
Age $\geq 80 \mathrm{y}, \mathrm{n}(\%)$ & $288(71.7)$ & $687(71.3)$ & 0.084 \\
Prosthetic IE, n (\%) & $324(80.8)$ & $762(79.5)$ & 0.932 \\
Fever, n(\%) & $206(50.9)$ & $468(48.6)$ & 0.598 \\
Heart failure, n(\%) & $73(18.0)$ & $139(14.4)$ & 0.094 \\
Sepsis with MOD, n(\%) & $57(14.1)$ & $90(9.3)$ & 0.010 \\
Septic shock, n(\%) & $79(19.5)$ & $162(16.2)$ & 0.234 \\
S. aureus IE, n(\%) & $125(30.9)$ & $178(18.5)$ & $<0.001$ \\
In-hospital mortality, n(\%) & $36(5.1)$ & 0.001 \\
One-year mortality, n(\%) & $28(10.9)$ & &
\end{tabular}

IE: infective Endocarditis. CCI: Charlson Comorbidity Index. SD: standard deviation. MOD: multiple organ dysfunction.

a Two-tailed Chi-squared test or Fisher's exact test (as corresponding) for categorical variables and ANOVA test for continuous variables. 
Table 6

Sensitivity, specificity, positive predictive value, negative predictive value, and accuracy for CCI $\geq 3$ to predict in-hospital and 1-year mortality in 2011 patients with surgical indication for IE.

\begin{tabular}{|c|c|c|c|c|c|c|}
\hline & Dead (TP/total) & Alive (TN/total) & $\frac{\text { Sensitivity (\%) }}{(95 \% \mathrm{CI})}$ & $\begin{array}{l}\text { Specificity (\%) } \\
(95 \% \mathrm{CI})\end{array}$ & $\begin{array}{l}\text { PPV (\%) } \\
(95 \% \mathrm{CI})\end{array}$ & $\begin{array}{l}\text { NPV (\%) } \\
(95 \% \text { CI })\end{array}$ \\
\hline \multicolumn{7}{|l|}{ CCI $\geq 3$ for In-hospital mortality } \\
\hline Surgical indication and surgery & $125 / 303$ & $785 / 1065$ & $41.3(35.7-46.8)$ & 73.7 (71.1-76.4) & $30.9(26.4-35.4)$ & $81.5(79.1-84.0)$ \\
\hline Surgical indication and no surgery & $190 / 351$ & $171 / 292$ & $54.1(48.9-59.3)$ & $58.5(52.9-64.2)$ & $61.1(55.7-66.5)$ & $51.5(46.1-56.9)$ \\
\hline \multicolumn{7}{|l|}{$\mathrm{CCI} \geq 3$ for one-year mortality } \\
\hline Surgical indication and no surgery & $29 / 57$ & $128 / 208$ & $50.9(37.9-63.9)$ & $61.5(54.9-68.2)$ & $26.6(18.3-34.9)$ & $82.1(76.0-88.1)$ \\
\hline
\end{tabular}

CCI: Charlson Comorbidity Index; IE: infective Endocarditis; TN: true negative; TP: true positive; CI: confidence interval; PPV: positive predictive value; NPV: negative predictive value.

From these results, we analysed whether $\mathrm{CCI} \geq 3$ could predict inhospital and 1-year mortality among patients with surgical indication, helping to select the best candidates for surgery (Table 4). Overall, for in-hospital mortality, CCI $\geq 3$ showed a sensitivity and specificity of $48.2 \%$ and $70.5 \%$, respectively; the PPV was $44.0 \%$ and NPV $73.8 \%$. For 1 -year mortality, CCI $\geq 3$ showed a sensitivity and specificity of $47.1 \%$ and $72.2 \%$, respectively, with a PPV of $15.5 \%$ and NPV of $92.6 \%$ (Table 6).

The AUROC for CCI was 0.64 (CI: 0.62-0.67) for the prediction of in-hospital mortality (Fig. $1 \mathrm{~A}$ ) and 0.65 (CI: 0.60-0.70) for 1-year mortality (Fig. 1 C). When the three age groups compared, the AUROC curve for CCI was significantly larger for patients aged $<65$ years than for those aged 65 to 79 years or $\geq 80$ years for in-hospital mortality (0.67 [95\% CI: $0.63-0.71]$ vs. 0.62 [95\% CI: $0.58-0.66$ ] vs. 0.54 [95\% CI: 0.48-0.61], respectively; $p<0.001$; Fig. 1B). These results were similar for 1-year mortality: age < 65 years: 0.70 (95\% CI: $0.61-0.79$ ), age 65 to 79 years: 0.63 (95\% CI: $0.55-0.71$ ), and $\geq 80$ years: 0.46 (95\% CI: 0.34-0.58; $p<0.001$; Fig. 1D).

\section{Discussion}

This multicentric prospective study evaluates the main epidemiological characteristics of patients with IE in different age groups. It is worth noting the high proportion of older patients with IE in our study, since this special population currently presents an increasing incidence of IE $[5,7,9,10]$. As it has been observed in other studies, IE was more frequent in male patients, probably due to the higher proportion of valvular disease in this population. [14,19]. The increasing in the proportion of female patients with age could be related to the higher life expectancy of women [8]. It is accepted that older patients presented more comorbidities $[8,14,15]$. We found two exceptions: the presence of liver disease and the percentage of solid organ transplant recipients, both of them more frequent in younger patients. First condition could be related to the higher mortality of patients with advanced liver disease. Solid organ transplants are also performed more frequently in younger patients, although due to the small proportion of patients is difficult to draw conclusions about this finding.

Fever and heart failure were the most common presentations of IE, with no differences among age groups. These results are consistent with the current evidence since, although it has been usually accepted that clinical features are less marked in older people than in younger patients [2,10], recent studies do not find clear differences in clinical presentation between both groups $[14,15]$. The higher frequency of a new heart murmur in the $<65$-year group could be related to the misattribution of cardiac murmurs in older patients to degenerative valvular disease, which is more frequent in this population. Therefore, the diagnosis of IE could be challenging, but main signs and symptoms of presentation do not seem very different between younger and older patients.

Cases of IE with $S$. viridans isolation were more common in patients aged $<65$ years, while cases of IE with $S$. bovis and Enterococcus spp. isolation were more prevalent in patients older than 80 years, probably related to the more frequent odontogenic origin of IE in the younger population and to the gastrointestinal and genitourinary origin in octogenarian patients $[8,14,15,33]$. The isolation of the CoNS was more frequent in the group of 65 to 79 years, which could be explained by the higher proportion of prosthetic valve IE and nosocomial IE among these patients $[5,8]$. Similarly, to other studies, we did not find differences among all three groups in the proportion of gram-negative bacilli and Candida spp. IE, as well as in the proportion of IE without microbiologic isolation $[14,19]$.

Mortality among our patients was high, especially in elder patients, as has been remarked in other studies $[2,7,15,17,33,34]$. There is no doubt that the greater degree of comorbidity that these patients presented has contributed to this. On the other hand, the value of surgery in the outcome of IE is well known [35]. Our data showed that increasing age, in particular the oldest old patients ( $\geq 80$ years), CCI $\geq 3$, and non-performance of surgery were independently associated with mortality.

In all three groups, the proportion in whom surgery was performed was less than the surgical indication. However, we found that the percentage of patients $\geq 80$ years who underwent surgery was significantly lower compared with other age groups. Only $21 \%$ of the octogenarian group underwent surgery, although surgical intervention was indicated in $52 \%$. This fact means that $31 \%$ of patients aged $\geq 80$ years with surgical indications did not undergo surgery, compared with $14 \%$ or $20 \%$ in the groups of $<65$ years and 65 to 79 years, respectively. Thus, in our cohort, the non-performance of surgery in patients in whom it was indicated could also contribute to the higher mortality rate observed in older patients. The results agree with the findings by Oliver et al. [19], who showed that very old patients with IE could benefit from surgery, since mortality in surgical candidates reached $72.7 \%$ in the case of medical treatment alone compared with $6.3 \%$ for patients who received both medical and surgical treatment. In addition, in our study, patients $\geq 80$ years who underwent surgery did not present more complications than the other groups of patients and had significantly fewer hemodynamic complications or renal failure. Nonetheless, these results must be interpreted with caution since the operated patients had a stricter selection and significantly less hemodynamic instability or complexity of surgery than in the other age groups. However, a negative of patient and a negative of surgeon were the main reasons for non-performance of surgery in the older patients. As suggested by Chirillo [13], age per se should not be a contraindication to surgery.

Given these findings, we studied whether the degree of comorbidity calculated by the ICC could be useful to select patients with lower 

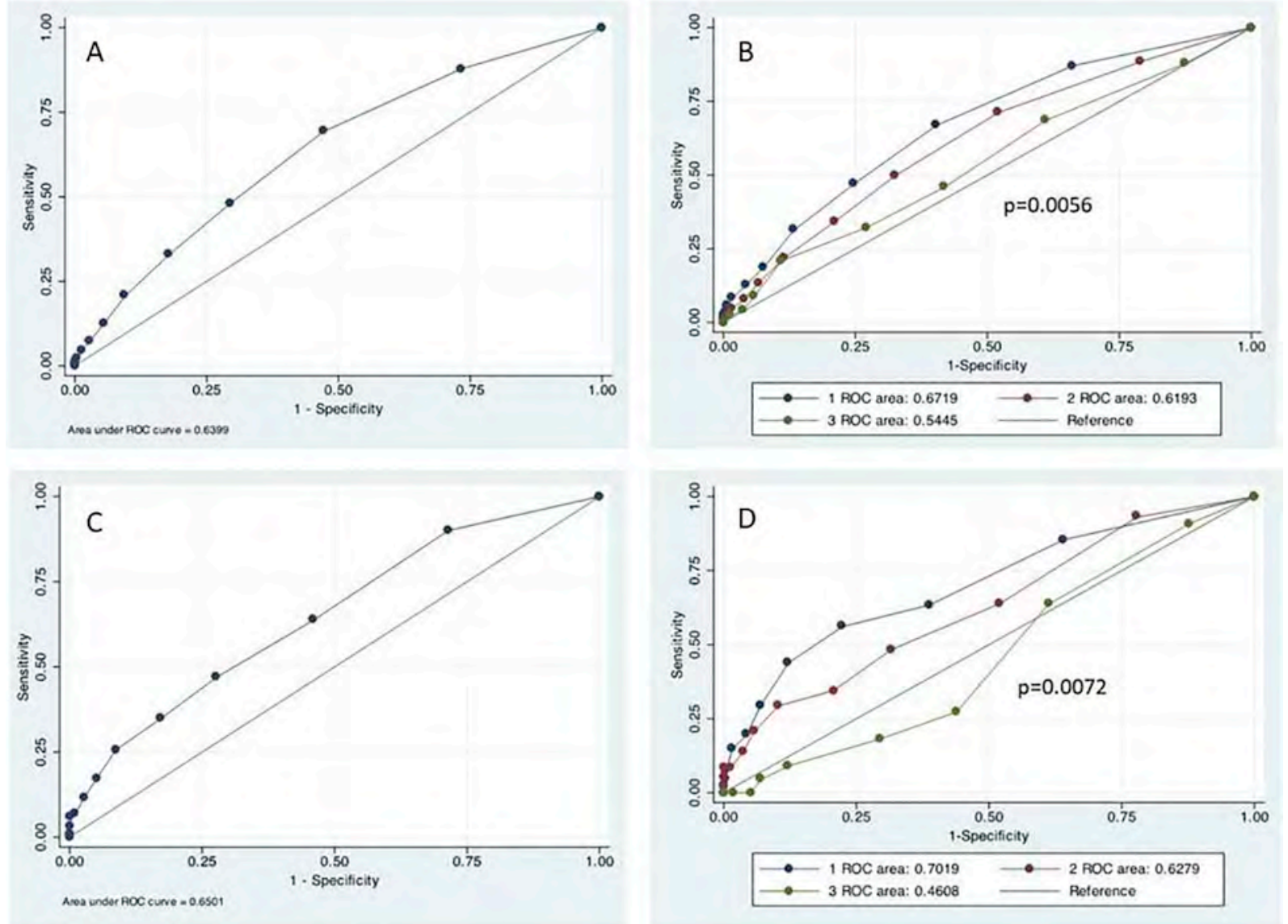

Fig. 1. ROC curves to assess the accuracy of the CCI in predicting in-hospital and 1 year-mortality according to CCI in 2011 patients with surgical indication (global and distributed by age group: group 1: patients $<65$ years; group 2: patients 65 to 79 years; group 3: patients $\geq 80$ years) A: Global in-hospital mortality; B: Inhospital mortality comparing age groups; C: Global 1-year mortality; D: 1-year mortality comparing age groups.

surgical risk. The CCI was applied to all patients with surgical indication. The score showed a high negative predictive value for in-hospital and 1-year mortality, especially in the group of patients aged $<65$ years who underwent surgery. The modest value of the AUROC curve in patients aged 65 to 80 years and in those $\geq 80$ years make us take these results with caution in those populations.

This study presents some limitations. It is part of a multicentre collection of data, and some recordings of clinical or diagnostic characteristics might be influenced by interobserver variability. Second, not all participating hospitals have a Cardiovascular Surgery Service, although all of them have a referral hospital, with cardiovascular surgeons as part of their IE teams. Finally, our data form did not include scales of basal situation and frailty, which, if associated with comorbidity, could better estimate the daily condition of older patients with IE. Nevertheless, this study shows one of the largest multicentric published cohorts, with a clearly established protocol, which allows us to analyse the effect of age and comorbidity on the outcome of IE.

In view of our results, we can conclude that mortality, both inhospital and at 1 year, remains high in IE, being age, comorbidity and non-performance of surgery independent predictors of mortality. Therefore, it is necessary to individualize the most appropriate treatment in older patients, in order to identify best candidates of surgery in that population. Preoperative multidisciplinary evaluation (cardiologist, cardiac surgeons, specialists in geriatrics, in infectious diseases) in each patient is essential to evaluate the benefit and the risk of the operation, and professionals with experience in the assessment of elderly patients could enrich the IE teams.

\section{Conflicts of interest}

Dr. Miro reports grants and personal fees from AbbVie, Angelini, Bristol-Myers Squibb, Contrafect, Jansen, Genentech, Medtronic, Merck, Novartis, Gilead Sciences, and ViiV Healthcare, outside the submitted work.

Dr. Ojeda-Burgos reports non-financial support from Sanofi Aventis, personal fees and non-financial support from Gilead, personal fees and non-financial support from Merck Sharp Dohme de España SA, nonfinancial support from Angelini, non-financial support from Janssen, outside the submitted work.

All the other authors report no conflict of interest.

\section{Acknowledgements}

This research did not receive any specific grant for funding.This work was partially presented at the 27th European Society of Clinical Microbiology and Infectious Diseases Congress in Vienna, in 2017.

\section{References}

[1] Fernández-Hidalgo N, Tornos Mas P. Epidemiology of infective endocarditis in Spain in the last 20 years. Rev Esp Cardiol 2013;66:728-33.

[2] Forestier E, Fraisse T, Roubaud-Baudron C, Selton-Suty C, Pagani L. Managing infective endocarditis in the elderly: new issues for an old disease. Clin Interv Aging 2016;11:1199-206

[3] Alonso-Valle H, Fariñas-Alvarez C, Bernal-Marco JM, García-Palomo JD, GutiérrezDíez F, Martín-Durán R, et al. The changing face of prosthetic valve endocarditis at a tertiary-care hospital: 1986-2005. Rev Esp Cardiol 2010;63:28-35.

[4] Fariñas MC, Pérez-Vázquez A, Fariñas-Alvarez C, García-Palomo JD, Bernal JM, Revuelta JM, et al. Risk factors of prosthetic valve endocarditis: a case-control 
study. Ann Thorac Surg 2006;81:1284-90.

[5] Cresti A, Chiavarelli M, Scalese M, Nencioni C, Valentini S, Guerrini F, et al. Epidemiological and mortality trends in infective endocarditis, a 17-year population-based prospective study. Cardiovasc Diagn Ther 2017;7:27-35.

[6] Castillo Domínguez JC, Anguita Sánchez MP, Ramírez Moreno A, Siles Rubio JR, Mesa Rubio D. Muñoz Carvajal I et al. clinical features and prognosis of infective endocarditis in the elderly. Rev Esp Cardiol 2000;53:1437-42.

[7] Cahill TJ, Baddour LM, Habib G, Hoen B, Salaun E, Pettersson GB, et al. Challenges in infective endocarditis. J Am Coll Cardiol 2017;69:325-44.

[8] López J, Revilla A, Vilacosta I, Sevilla T, Villacorta E, Sarria C, et al. Age-dependent profile of left-sided infective endocarditis. Circulation 2010;121:892-7.

[9] Cecchi E, Chirillo F, Castiglione A, Faggiano P, Cecconi M, Moreo A, et al. Clinical epidemiology in Italian registry of infective endocarditis: focus on age, intravascular devices and enterococci. Int J Cardiol 2015;190:151-6.

[10] Gregoratos G. Infective endocarditis in the elderly: diagnosis and management. Am J Geriatr Cardiol 2003;12:183-9.

[11] Selton-Suty C, Hoen B, Grentzinger A, Houplon P, Maignan M, Juillière Y, et al, Clinical and bacteriological characteristics of infective endocarditis in the elderly. Heart 1997;77:260-3.

[12] Carrasco Ávalos F, Hidalgo Lesmes FJ, Ruiz Ortiz M, Anguita Sánchez M. Early prosthetic valve infective endocarditis in the elderly: changes over a 28-year period (1987-2014). Rev Clin Esp 2017;217:174-6.

[13] Chirillo F. It is not how old you are, it is how you are old: need for changes in the management of infective endocarditis in the elderly. Heart 2017;103:1562-4.

[14] López -Wolf D, Vilacosta I, San Román JA, Fernández C, Sarria C, López J, et al. Infective endocarditis in octogenarian patients. Rev Esp Cardiol 2011;64:329-33.

[15] Bassetti M, Venturini S, Crapis M, Ansaldi F, Orsi A, Della Mattia A, et al. Infective endocarditis in elderly: an Italian prospective multi-center observational study. Int J Cardiol 2014;177:636-8.

[16] Remadi JP, Nadji G, Goissen T, Zomvuama NA, Sorel C, Tribouilloy C. Infective endocarditis in elderly patients: clinical characteristics and outcome. Eur J Cardiothorac Surg 2009;35:123-9.

[17] Durante-Mangoni E, Bradley S, Selton-Suty C, Tripodi MF, Barsic B, Bouza E, et al. Current features of infective endocarditis in elderly patients: results of the international collaboration on endocarditis prospective cohort study. Arch Intern Med 2008;168:2095-103.

[18] Ramírez-Duque N, García-Cabrera E, Ivanova-Georgieva R, Nou-reddine M, Lomas JM, Hidalgo-Tenorio C, et al. Surgical treatment for infective endocarditis in elderly patients. J Infect 2011;63:131-8.

[19] Oliver L, Lavoute C, Giorgi R, Salaun E, Hubert S, Casalta JP, et al. Infective endocarditis in octogenarians. Heart 2017;103:1602-9.

[20] Wang A, Gaca JG, Chu VH. Management considerations in infective endocarditis: a review. JAMA 2018;320:72-83.

[21] Baddour LM, Wilson WR, Bayer AS, Fowler Jr. VG, Tleyjeh IM, Rybak MJ, et al. Infective endocarditis in adults: diagnosis, antimicrobial therapy, and Management of Complications: a scientific statement for healthcare professionals from the American Heart Association. Circulation 2015;132:1435-86.
[22] Habib G, Lancellotti P, Antunes MJ, Bongiorni MG, Casalta JP, Del Zotti F et al. 2015 ESC guidelines for the management of infective endocarditis: the task force for the management of infective Endocarditis of the European Society of Cardiology (ESC). Endorsed by: European Association for Cardio-Thoracic Surgery (EACTS), the European Association of Nuclear Medicine (EANM). Eur Heart J; 36: 3075-3128.2015.

[23] Gatti G, Perrotti A, Obadia JF, Duval X, Iung B, Alla F, et al. Association for the Study and Prevention of infective endocarditis study group-association pour l'Étude et la Prévention de l'Endocadite Infectieuse (AEPEI). Simple scoring system to predict in-hospital mortality after surgery for infective endocarditis. J Am Heart Assoc 2017 Jul 20;6(7).

[24] Gatti G, Benussi B, Gripshi F, Della Mattia A, Proclemer A, Cannatà A, et al. A risk factor analysis for in-hospital mortality after surgery for infective endocarditis and a proposal of a new predictive scoring system. Infection 2017 Aug;45(4):413-23.

[25] Charlson M, Pompei P, Ales KL, McKenzie CR. A new method of classyfing prognostic comorbidity in longitudinal studies: development and validation. J Chronic Dis 1987;40:373-83.

[26] Charlson M, Szatrowski TP, Peterson J, Gold J. Validation of a combined comorbidity index. J Clin Epidemiol 1994;47:1245-51.

[27] Stavem K, Hoel H, Skjaker SA, Haagensen R. Charlson comorbidity index derived from chart review or administrative data: agreement and prediction of mortality in intensive care patients. Clin Epidemiol 2017;9:311-20.

[28] Armiñanzas C, Velasco L, Calvo N, Portilla R, Riancho JA, Valero C. CURB-65 as an initial prognostic score in internal medicine patients. Eur J Intern Med 2013;24:416-9.

[29] Saji M, Katz MR, Ailawadi G, Fowler DE, Ragosta M, Lim DS. Predictive value of age-adjusted Charlson co-morbidity index for 1-, 3-, and 5-year mortality in patients requiring transcatheter mitral valve repair. Am J Cardiol 2017;120:309-14.

[30] Durack DT, Lukes AS, Bright DK. New criteria for diagnosis of infective endocarditis: utilization of specific echocardiographic findings duke endocarditis service. Am J Med 1994;96:200-9.

[31] Li JS, Sexton DJ, Mick N, Nettles R, Fowler Jr. VG, Ryan T, et al. Proposed modifications to the duke criteria for the diagnosis of infective endocarditis. Clin Infect Dis 2000;30:633-8.

[32] Muñoz P, Kestler M, De Alarcon A, Miro JM, Bermejo J, Rodríguez-Abella H, et al. Current epidemiology and outcome of infective endocarditis: a multicenter, prospective, cohort study. Med (Baltimore) 2015;94(43):e1816.

[33] Slipczuk L, Codolosa JN, Davila CD, Romero-Corral A, Yun J, Pressman GS, et al. Infective endocarditis epidemiology over five decades: a systematic review. PLoS One 2013;8:e82665.

[34] Selton-Suty C, Célard M, Le Moing V, Doco-Lecompte T, Chirouze C, Iung B, et al Preeminence of Staphylococcus aureus in infective endocarditis: a 1-year populationbased survey. Clin Infect Dis 2012;54:1230-9.

[35] Alonso-Valle H, Fariñas-Alvarez C, García-Palomo JD, Bernal JM, Martín-Durán R, Gutiérrez Díez JF, et al. Clinical course and predictors of death in prosthetic valve endocarditis over a 20-year period. J Thorac Cardiovasc Surg 2010;139:887-93. 